\title{
Study on the Examination Management under Standardized Examination Conditions
}

\author{
Fang Liu ${ }^{1, a}$, Yifeng $X u^{1, b}$ \\ ${ }^{1}$ Pingxiang University, Pingxiang, Jiangxi, 337055 \\ ${ }^{\mathrm{a}}$ email, ${ }^{\mathrm{b}}$ email
}

Keywords: Examination Management, Standardized Examination, Cheat

\begin{abstract}
After the expedition system was established, test scores and the vital interests of the candidates tied, examination fraud also produced, and with the close connection with the examination of fame and fortune and malignant development (from the ancient imperial examinations to test a variety of modern, people are trying to do everything possible to get rid of this "cancer": in the test management, to take all sorts of strict measures, layers of fortification; evolved from the ancient to the modern search using metal detectors to check, they are trying to eliminate candidates who bring prohibited items into the examination room examination way, but exam cheating tricks: entrainment, copy, test taking, etc; in particular, to the modern, mobile phones, electronic scanning pen, wireless headsets, glasses endless transmission cheats, cheat groups, organized cheating, using high-tech cheating showing a tendency to spread, more and more difficult to defend, how to prevent cheating candidates, especially the organized groups of cheating, the use of high-tech cheating has become the most important issue of modern research manager exam.
\end{abstract}

\section{Introduction}

Development of information technology and network technology are to promote the rapid development of standardized examination room. Standardized exam as a new management model, which effectively changed the traditional examination room management model to promote the exam more transparency, impartiality and fairness, is conducive to education for sustainable development. The traditional examination management terms compared, test management under standardized examination conditions need to be in the actual development of refined and improved, thereby fulfilling their own anti-fraud function promote vocational and professional development of test management.

\section{Standardized Examination Meanings}

Standardized exam is developed on the basis of the general examination evolved, reservations, but more of a transformation and upgrading; standardized examination room examination room is located in the school retains the usual practice, but is required to be provided in junior high school or more, mainly Taking into account the long-term you want to use a standardized exam, exam equipment for adults candidates ordinary examination room does not have this requirement. Examination capacity generally are 30 candidates, use of existing school desks and chairs, front to back are arranged in a serpentine; standardized exam to retain the traditional practice exam seat number and serpentine arrangement, but the starting point must be the provisions seat number face candidates, right invigilator's first front row table, but are arranged in the form of 7,7,8,8 four rows.

Standardize the examination room more functional and unity. All test sites within the examination room according to a unified set of requirements, including inside and outside the examination room network monitoring, monitoring system, standardized test language distribution system, the campus radio system, clock calibration systems, test emergency command system, both inside and outside the examination room information blocking system.

It can be said that the powerful anti-fraud function is a basic function of a standardized exam. With the progress of society, science and technology continue to develop innovative, high-tech products continue to emerge, spread and access to information means more and more, more and 
more secretive. Reflected in the test field, it is that some candidates use high-tech means of fraud. To test the field of fraud control the spread of the importance of using high-tech means to prevent, in addition, no other way. Standardized exam is the bane of high-tech fraud: its online exam inspection subsystem may realize multi-level online inspections of the entire process of examination and implementation of comprehensive real-time video surveillance, can effectively prevent the occurrence of candidates cheating; information inside and outside the examination room blocking subsystem, can effectively prevent the communication between the candidates and the examination room, which is equipped with metal detectors capable mobile phones, wireless headsets and other items with metal materials cheat stop outside the examination room, examination room invigilators surveillance cameras can , panoramic view of the candidate's every move and truthfully record keeping, entrainment, copy, transfer, collusion, language, gestures and other cheating, surveillance cameras can not escape his stuff; shield wireless device can effectively prevent the candidates and outside the examination room between signal contact; cheat Tethys discovery and search out candidates using a wireless headset. Examination surveillance cameras not only an attempt to deter cheating candidates, and video data processing is strong evidence of cheating. From the examination of the case of multiple provinces, the standardized exam really curb the spread of exam fraud, cheating on exams, a sharp decline in fraud, the examination room order was restored to normal. The primary function standardized examination has shown its great power, but also indicates a standardized exam future development prospects and vitality.

\section{Test Management Problems and Its Reasons}

As a result of a "hierarchical management, progressively responsible" management model, the provincial, city and county (district) many businesses are between three escalation, approval, spent a lot of time, manpower and material resources, thereby increasing the cost of the examination affairs. In addition, with the increase in the number of rural candidates, the Ministry of Education after the approval of the record, with the conditions of the county may be provided test sites. Set up test sites in the county, not only increased the difficulty of test management, but also further improve the Examination costs. Because relatively speaking, a small county, people familiar with the disturbing social network for examinations, the impact is relatively large, the county test center examination management work harder to achieve standardization.

The main problem is exam cheating, fraud has increased every year this discipline, a form of cheating are diversified and covert trend, but with high-tech color. For example, using a wireless headset cheating, this high-tech means of cheating than the previous entrainment, peeking means more covert. Even more serious is the emergence of "gunmen" collective cheating, invigilators, Proctors collusion with the candidates and so on. Before every major exam, looking for "gunmen" small ads everywhere on campus, college students and even some ads posted initiative, said he was able to act as "gunmen." Although the Ministry of Education has issued the relevant specific "gunmen" a penalty, but due to various reasons, "gunmen" did not stop there. Occasional collective cheating, better reflect the current problems, such as Hubei Ezhou Self collective cheating incident. More alarming is that cheating is not only the main candidates, as well as invigilators, examination management personnel, this "police" and "thief" conspiracy cases are not uncommon. Thereby resulting in some distortion test scores, undermined the authority of self-examination, impartiality.

Relying on administrative regulations to administer the exam is difficult to meet the actual needs of administering the test, mainly reflected in: First, the specification does not sufficiently punitive. In the current administrative regulations, mostly candidates violation penalties, fewer regulatory requirements concerning the implementation of the subject in the implementation process, the administrative department of education and examination bodies according to the law is difficult to truly test, self-discipline subject behavior, norms object behavior. Second, the force of law is weak, judicial interpretation in a passive position. "Education Law", "Higher Education Law" was promulgated to standardize the main educational activities in China. But when people of "all kinds of behavior and conduct education exam what is subordinate, parallel, mutually reinforcing relationship or the relationship between several co-exist," this proposition is not yet fully clear, the 
past so that the processing of exam cheating some effective regulations, when judicial interpretation often in a more awkward position, difficult to play to maintain the examination rules, strict role in the actual operation. Third, the department under the stability inferior law, the extent is difficult to ensure the implementation of its provisions do not change due to the time change; department under the law is less than the extension in space is difficult to coordinate and regulate the education sector consistent with other departments conduct examinations sex.

Organizations need to generate test exam transaction management and it is essentially a social service organization. From the interest, the value of its existence is not profit, but to provide maximum services to the public interest. But in fact, the examination of test management organization not pay enough attention, causing a lot of problems Examination management, this is only appearance, which has deep interests of the game behind. Examination organization not unaware of the examination management is not in place, but do not want to test the organization and management in place. The reason is very simple: once the examination management was very strict, candidates will become less direct economic benefits will decline. In the current year after year colleges and universities and secondary enrollment surge in independent college background, the situation is increasingly difficult to survive tests, the number of students directly affected. Some managers believe that the quality and test management is inversely proportional to students, they think that if management is too strict, easy to pass the exam, learners are likely to choose other ways to study, which will lead to the loss of students; on the contrary they are Self will choose.. Thus, in order to win the candidate's "identity", to keep the students, the organization resorted to relax exam test management "trick" the.

\section{Effective Strategies Standardized of Exam Conditions}

For standardized examination, if the traditional management concepts and it can not function and role of standardized examination to effectively play. In the past mostly from teaching in the school for the establishment of the examination room, which makes the examination room has greater mobility, while the long-term use of a standardized examination and fixity, which requires school leaders and teachers have high quality, organizational skills as well as at work. Currently, in the organization of the examination, exam training for teachers using the way, but because of personal ability and receiving different training efforts, resulting examiner effect and efficiency of the work of different will inevitably lead to errors in the work of the phenomenon. For test management under standardized conditions in terms of the examination room, it must break the traditional mode of management, and actively change their ideas, to strengthen the ranks of the test professionalism and specialization. For all examination staff rigorous professional examination and training can be carried out only after its work related to the examination qualified. At the same time should increase the remuneration for their work and attract the relevant teachers and social workers, improve staff enthusiasm and initiative participation, to ensure the smooth implementation of test management work.

For test management under standardized examination conditions, most of the training school invigilator is more attention, but ignored the patrol officer exam training and exam management, leading to difficult to handle management and inspection personnel monitoring devices, can only resort the operator control room. In this way greatly reduces the management and motivation of personnel patrol, prompting operator workload increase. Therefore test management work performed under standardized examination conditions, we must strengthen the training and examination staff to improve their professional quality, reasonable hierarchical way of training, only to participate in related work after the training of qualified.

The main purpose of the examination is to be sure the candidates own knowledge and ability enhance the competitiveness of society and the overall quality of the candidates. Test management personnel during test management work, must be a clear understanding of the candidates is the subject of the examination, the examination system and incorporates relevant, actively help and guide the candidates, the implementation of humane management, for the candidates to provide a good test environment. Such as Candidates forget to bring ID card, may be composed of police 
officers in the examination room online confirmation; candidates forget to bring ticket, they can apply for test sites in the examination affairs office and to be downloaded from the Internet. In addition, under standardized examination conditions humanistic examination management, it must comply with the relevant system, and actively change management concepts to meet the actual needs of the candidates on the basis of licensing examination system and legal, effective help and guide the candidates to solve problems.

\section{Conclusion}

In today's rapid development of science and technology, standardized examination room appeared at the same time. Similarly, test management also needs to follow a standardized examination to establish continuous development and improvement. Examination management under standardized examination conditions are not yet mature, test management staff needs to continue to strengthen the management measures of inquiry to find out the efficient management and maintenance of a fair and impartial examination.

\section{Acknowledgements}

A new round reform of the education system of examination and enrollment of research projects (1558/1524),

2014 Jiangxi Education Reform Project (JXJG-14-22-6),

2015 Education Department of Jiangxi Party building issues (JXGXDJKT.GH-201513).

\section{References}

[1] Li Lingqin. Equity of Entrance Examination of [D]. Nanchang University 2012

[2] Zhang Hui. Imperial Examination System and Its Implications for China College Entrance Examination Reform [D]. Hebei Normal University, 2010

[3] Dong Dandan. Since 1978, the Fairness of University Entrance Examination [D]. Fujian Normal University, 2011

[4] Zhu Shu. Comparative Study of the United States and China the SAT college entrance examination in the [D]. Nanchang University 2011

[5] Sun Wenwen. Based Entrance Examination System Reform Education Equity under the research [D]. Dongbei University of Finance and Economics 2011

[6] Liu Luochun. Historical Evolution and Reform Path Entrance Examination System Research [D]. Hunan Normal University, 2011 